\title{
The incorporation of
}

\section{linoleic acid into the plasma lipids of sheep given intraruminal infusions of maize oil or free linoleic acid}

\author{
By R. C. NOBLE, W. STEELE AND J. H. MOORE \\ Hannah Dairy Research Institute, Ayr
}

(Received 3 February 1969-Accepted 14 March I969)

\begin{abstract}
I. The fatty acid compositions of the plasma cholesteryl esters, phospholipids, triglycerides and unesterified fatty acids were determined in two sheep at various times after they had been given intraruminal infusions of emulsions of maize oil or linoleic acid.

2. The concentration of linoleic acid in the plasma triglycerides began to increase $3 \mathrm{~h}$ after infusion began. The infusions of maize oil and linoleic acid resulted in the appearance of peak concentrations of linoleic acid in the plasma triglycerides 6 and $12 \mathrm{~h}$ respectively after infusion began.

3. After the infusion of maize oil the plasma triglycerides showed an increase in the concentration of stearic acid but after the infusion of linoleic acid the plasma triglycerides showed an increase in the concentration of oleic acid.

4. The concentration of linoleic acid in the plasma phospholipids and cholesteryl esters did not begin to increase until $6-9 \mathrm{~h}$ and $24-25 \mathrm{~h}$ respectively after the infusions had begun.

5. No evidence was found for an absorption mechanism which involved the direct incorporation of linoleic acid into the blood phospholipids or cholesteryl esters.
\end{abstract}

Under normal conditions the polyunsaturated acids in the lipids of the blood plasma of sheep appear to be selectively incorporated into the cholesteryl ester and phospholipid fractions. In spite of the extensive hydrogenation of dietary polyunsaturated fatty acids that occurs in the rumen (Tove \& Mochrie, 1963), it has been shown that the polyunsaturated fatty acid compositions of the plasma cholesteryl esters and phospholipids are determined, to some extent, by the polyunsaturated fatty acid composition of the diet (Moore, Noble \& Steele, I968). Thus, previous work with sheep showed that the replacement of hay (low linolenic:linoleic acid ratio) in the diet by dried grass (high linolenic: linoleic acid ratio) resulted in increased concentrations of linolenic acid and decreased concentrations of linoleic acid in the plasma cholesteryl esters and phospholipids; there were no significant effects on the concentrations of the $\mathrm{C}_{18}$ polyunsaturated acid in the plasma triglyceride and unesterified fatty acid fractions (Moore et al. 1968). It has also been shown from work involving the infusion into the abomasum of high levels of triglycerides containing polyunsaturated acids (Moore et al. 1969) that there is no reason to suppose that the mechanisms of digestion and absorption of such triglycerides in the lower gut of the ruminant are any different from the mechanisms that are known to operate in monogastric animals (Senior, 1964). Infusion of polyunsaturated fatty acids in the free form into the abomasum resulted in a pattern of fatty acid incorporation into the plasma lipid fractions similar to that obtained when the fatty acids were infused in triglyceride form. Although the normal diet of the ruminant contains substantial amounts of polyunsaturated fatty acids, mainly in glyceride form, it is doubtful whether under normal circumstances any glycerides as such reach the small intestine owing to the effective hydrolysis that occurs in the 
rumen (Garton, Lough \& Vioque, I96I). In an attempt to elucidate further the mechanism by which the ruminant assimilates the $C_{18}$ polyunsaturated acids, two experiments were carried out in which large concentrations of linoleic acid, in either the free or triglyceride form, were infused into the rumen of sheep and the fatty acid compositions of the various plasma lipid classes determined at various times after the infusion. The results of these experiments are now reported.

\section{EXPERIMENTAL}

\section{Animals and diet}

Two adult wether sheep (weight approximately $65 \mathrm{~kg}$ ) of the Hampshire breed fitted with permanent rumen and abomasal fistulas were housed in individual metabolism cages. The sheep were given $900 \mathrm{~g}$ of hay/day in two equal portions, one at $07.00 \mathrm{~h}$ and one at $\mathrm{I} 6.00 \mathrm{~h}$. Water was given $\mathrm{ad} \mathrm{lib}$.

\section{Procedure}

The sheep were given the diet of hay for 28 days. In Expt I an emulsion of $4 \circ \mathrm{g}$ of maize oil triglycerides was infused at constant rate into the rumen of one of the sheep between 09.00 and $10.00 \mathrm{~h}$ on day 29 . In Expt 2 an emulsion of $40 \mathrm{~g}$ of 'linoleic' acid,

Table 1. Compositions of the fatty acids (major components, weight percentages of the total) present in the hay, maize oil and linoleic acid

$\begin{array}{crcc}\text { Fatty acid } & \text { Hay } & \text { Maize oil } & \text { 'Linoleic acid' } \\ \text { I6:0 } & 20.7 & 9 \cdot 9 & 15 \cdot 2 \\ \text { 16:1 } & 2.2 & - & 0.3 \\ 18: 0 & 5 \cdot 6 & 2 \cdot 1 & 2 \cdot 2 \\ 18: 1 & 18 \cdot 9 & 22.9 & 10 \cdot 9 \\ 18: 2 & 25.0 & 64.4 & 71 \cdot 1 \\ 18: 3 & 17.8 & 0.7 & -\end{array}$

obtained from Price's (Bromborough) Ltd, Bebington, Cheshire, was infused into the rumen of the other sheep between 09.00 and ro.00 $\mathrm{h}$ on the same day. The emulsions were prepared and infused by the methods described previously (Moore et al. 1968). The fatty acid compositions of the hay, maize oil and 'linoleic' acid are given in Table $\mathrm{I}$. Using a solution of trisodium citrate dihydrate $(3.8 \%, \mathrm{w} / \mathrm{v})$ as an anticoagulant, blood samples ( $10-15 \mathrm{ml}$ ) were taken immediately before and at various time intervals (see Tables 2-5) after the intraruminal infusions had begun. Hay was withheld from the sheep until after the period of infusion and sampling in Expt $\mathrm{I}$, whereas in Expt 2, the sheep was not given the $16.00 \mathrm{~h}$ meal on day 29 but normal feeding was resumed on the following day.

\section{Extraction of lipids and methods of analysis}

Extraction of the lipids and the methods used in their analysis have been described previously (Moore et al. 1968, 1969). 


\section{RESULTS}

The fatty acid compositions of the major plasma lipid fractions are given in Tables 2-5.

Expt $\mathrm{I}$ : maize oil infusion. The concentration of $18: 2$ in the triglyceride fraction increased after the and $h$, and reached a maximum concentration of $15 \%$ at the 6 th $h$.

Table 2. Effect of the infusion of an emulsion of maize oil into the rumen of a sheep on the fatty acid compositions (major components, weight percentages of the total) of the plasma triglycerides and unesterified fatty acids

\begin{tabular}{|c|c|c|c|c|c|c|c|c|c|c|}
\hline \multirow{2}{*}{$\begin{array}{l}\text { Time after } \\
\text { beginning } \\
\text { of infusion } \\
\text { (h) }\end{array}$} & \multicolumn{5}{|c|}{ Triglycerides } & \multicolumn{5}{|c|}{ Unesterified fatty acids } \\
\hline & $16: 0$ & $16: 1$ & $18: 0$ & $18: 1$ & $18: 2$ & $16: 0$ & $16: 1$ & $18: 0$ & 18:1 & I8:2 \\
\hline$\circ$ & $31 \cdot 0$ & $4 \cdot 0$ & $28 \cdot 2$ & $30 \div 4$ & $3 \cdot 9$ & $24 \cdot 2$ & $6 \cdot 7$ & $37 \circ 0$ & $29 \cdot 7$ & $2 \cdot 5$ \\
\hline 0.5 & $33 \cdot 6$ & $4 \cdot 0$ & $26 \cdot 9$ & $28 \cdot 9$ & $4 \div 9$ & $3 x \cdot 8$ & $2 \cdot 6$ & $42 \cdot 5$ & $2 I \cdot I$ & $2 \cdot 4$ \\
\hline $1 \cdot 0$ & $32 \cdot 5$ & 4.9 & $26 \cdot 4$ & $31 \cdot 4$ & $4 \cdot 8$ & $25 \cdot 9$ & 37 & $44 \cdot 1$ & $22 \cdot 2$ & $2 \cdot 1$ \\
\hline$x \cdot 5$ & $30 \cdot 1$ & $4 \cdot 2$ & $3 I \cdot 1$ & $28 \cdot 4$ & $2 \cdot 8$ & $24 \cdot 2$ & $2 \cdot 6$ & $43 \cdot 5$ & $27 \cdot 9$ & $2 \cdot 4$ \\
\hline $2 \cdot 0$ & $35 \cdot 2$ & $4: 2$ & $28 \cdot 6$ & $27 \cdot 5$ & $2 \cdot 1$ & $31 \cdot 9$ & $4 \cdot 4$ & $37 \cdot 4$ & $22 \cdot 7$ & 3.7 \\
\hline $3 \cdot 0$ & $27 \cdot 3$ & $3 \cdot 2$ & $26 \cdot 1$ & 33.7 & $6 \cdot 9$ & $39 \cdot 0$ & $4 \cdot 2$ & $38 \cdot 5$ & $13 \cdot 0$ & $5 \cdot 4$ \\
\hline $4 \cdot 0$ & $29 \cdot 8$ & 3.0 & $22 \cdot 5$ & $32 \cdot 6$ & 10.0 & $39 \cdot 3$ & 3.6 & $38 \cdot 4$ & 15.8 & 3.0 \\
\hline $6 \cdot 0$ & 23.2 & $2 \cdot 4$ & $2 I \cdot 2$ & $35 \cdot 7$ & $15 \cdot 1$ & $29 \cdot 2$ & $2 \cdot 7$ & 33.9 & 23.9 & II.O \\
\hline 8.0 & $31 \cdot 0$ & $3 \cdot 2$ & $25 \cdot 1$ & 30.4 & $9 \cdot I$ & $29 \cdot 7$ & $x \cdot 9$ & 32.5 & $26 \cdot 6$ & $9^{\cdot I}$ \\
\hline 24.0 & $2 I \cdot I$ & $4 \cdot 1$ & $45^{\circ} 0$ & $25 \cdot 7$ & $2 \cdot 8$ & $35^{\cdot 2}$ & $3 \cdot 4$ & 37.6 & $20 \cdot I$ & 3.4 \\
\hline
\end{tabular}

Table 3. Effect on the infusion of an emulsion of maize oil into the rumen of a sheep on the fatty acid compositions (major components, weight percentages of the total) of the plasma cholesteryl esters and phospholipids

\begin{tabular}{|c|c|c|c|c|c|c|c|}
\hline $\begin{array}{l}\text { Time after } \\
\text { beginning } \\
\text { of infusion }\end{array}$ & $16: 0$ & $16: 1$ & 18:0 & $18: 1$ & 18:2 & $18: 3$ & $20: 4$ \\
\hline (h) & \multicolumn{7}{|c|}{ Cholesteryl esters } \\
\hline$\circ$ & I5.O & $3 \cdot 0$ & 4.3 & $43 \cdot 3$ & $22 \cdot 4$ & $4 \cdot I$ & $2 \cdot 1$ \\
\hline 0.5 & $14: 3$ & $3 \cdot 0$ & $4 \cdot 0$ & $42 \cdot 0$ & $22 \cdot 1$ & 4.5 & $3 \cdot 2$ \\
\hline $1 \cdot 0$ & $16 \cdot 4$ & $2 \cdot 9$ & $4 \cdot 0$ & $4 I \cdot 3$ & $21 \cdot 4$ & $5 \cdot 2$ & $2 \cdot 5$ \\
\hline $1 \cdot 5$ & $18 \cdot 1$ & $2 \cdot 7$ & $5 \cdot 1$ & 40.5 & $20-5$ & $3 \cdot 9$ & $2 \cdot 8$ \\
\hline $2 \cdot 0$ & $17 \cdot 2$ & $2 \cdot 7$ & $4 \cdot 3$ & 40.7 & $2 I \cdot 3$ & $4 \cdot 4$ & $2 \cdot 9$ \\
\hline $3 \cdot 0$ & $17 \cdot 6$ & $2 \cdot 2$ & $6 \cdot 8$ & $3^{8 \cdot 6}$ & $24 \cdot 6$ & $3 \cdot 7$ & $2 \cdot 3$ \\
\hline $4 \cdot 0$ & 19.9 & $2 \cdot 5$ & $5 \cdot 6$ & $35 \cdot 9$ & $24 \cdot 0$ & 3.8 & $2 \cdot 4$ \\
\hline $6 \cdot 0$ & $16 \cdot 0$ & $2 \cdot 6$ & $5 \cdot 9$ & $4 I \cdot 6$ & $21 \cdot 8$ & $3 \cdot 9$ & $2 \cdot 8$ \\
\hline $8 \cdot 0$ & $27 \cdot 7$ & $2 \cdot 8$ & $3 \cdot 4$ & $40 \cdot 0$ & $21 \cdot 8$ & $4 \cdot 4$ & 3.4 \\
\hline \multirow[t]{2}{*}{$24 \cdot 0$} & I $4 \cdot 1$ & $2 \cdot 8$ & $3 \cdot 4$ & $38 \cdot 7$ & 29.1 & 3.9 & $2 \cdot 6$ \\
\hline & \multicolumn{7}{|c|}{ Phospholipids } \\
\hline 0 & $20 \cdot 5$ & 0.7 & $27 \cdot 7$ & $25 \cdot 2$ & II 9 & $2 \cdot 5$ & $5 \cdot 3$ \\
\hline 0.5 & $2 I \cdot 6$ & $I \cdot 2$ & $24 \cdot 6$ & $28 \cdot 0$ & $12 \cdot 4$ & 1.8 & 5.5 \\
\hline 1.0 & 19.0 & 0.8 & $29 \cdot 8$ & 25.5 & $11 \cdot 3$ & $2 \cdot 5$ & $5 \cdot 5$ \\
\hline $1 \cdot 5$ & 20.4 & $1 \cdot 0$ & $26 \cdot 5$ & 25.4 & 13.4 & $2 \cdot 0$ & $5 \cdot 7$ \\
\hline $2 \cdot 0$ & $19^{-1}$ & 0.7 & $27 \cdot 2$ & $25^{.8}$ & $13 \cdot 1$ & $2 \cdot 6$ & 5.4 \\
\hline $3 \cdot 0$ & $23 \cdot 8$ & $2 \cdot 0$ & $26 \cdot 2$ & 25.9 & II'I & $1 \cdot 7$ & $4 \cdot 9$ \\
\hline 4.0 & 20.5 & $1 \cdot 9$ & $28 \cdot 6$ & $28 \cdot 5$ & $10 \cdot 2$ & $1 \cdot 5$ & 4.4 \\
\hline $6 \cdot 0$ & 19.7 & $1 \cdot 2$ & $23 \cdot 9$ & 27.6 & 15.4 & $1 \cdot 6$ & 5.6 \\
\hline $8 \cdot 0$ & $19^{\circ} 0$ & $2 \cdot 0$ & 23.0 & $28 \cdot 7$ & $17 \cdot 2$ & $1 \cdot 5$ & 4.7 \\
\hline 24.0 & $18 \cdot 2$ & $I \cdot I$ & 24.9 & $20 \cdot 4$ & $25 \cdot 8$ & 0.9 & $4 \cdot 8$ \\
\hline
\end{tabular}


The concentration of $18: 2$ then declined until at the $24^{\text {th }} \mathrm{h}$ it had reverted to near its original value, at the same time decreases in the concentrations of $16: 0$ and $18: 0$ were noted. At the 24th $h$ the concentration of $16: 0$ was still lower than that found before infusion began but the concentration of $18: 0$ was considerably greater than the preinfusion value. The concentration of $18: 2$ in the unesterified fatty acid fraction of the plasma also reached a maximum value at the 6 th $\mathrm{h}$.

Although the concentrations of $18: 2$ in the cholesteryl esters and phospholipids did not show the rapid increase observed in the triglycerides and unesterified fatty acid fractions, there was nevertheless an overall increase in the concentration of $18: 2$ in these fractions over the sampling period. In the phospholipids the concentration of I 8: 2 began to increase after the 4 th $\mathrm{h}$; at the end of the sampling period the concentration of $18: 2$ had increased to $26 \%$ as compared with the pre-infusion concentration

Table 4. Effect of the infusion of an emulsion of 'linoleic' acid into the rumen of a sheep on the fatty acid compositions (major components, weight percentages of the total) of the plasma triglycerides and unesterified fatty acids

\begin{tabular}{|c|c|c|c|c|c|c|c|c|c|c|}
\hline \multirow{2}{*}{$\begin{array}{c}\text { Time after } \\
\text { beginning } \\
\text { of infusion } \\
\text { (h) }\end{array}$} & \multicolumn{5}{|c|}{ Triglycerides } & \multicolumn{5}{|c|}{ Unesterified fatty acids } \\
\hline & $16: 0$ & $16: 1$ & 18:0 & 18: I & $18: 2$ & I6:0 & $16: 1$ & 18:0 & I 8: I & $18: 2$ \\
\hline$\circ$ & $26 \cdot 3$ & $3 \cdot 2$ & $22 \cdot 0$ & $29 \cdot 3$ & $4^{*} 9$ & $18 \cdot 2$ & $3 \cdot 2$ & $21 \cdot 2$ & $46 \cdot 7$ & $2 \cdot 2$ \\
\hline 0.5 & $28 \cdot \mathrm{I}$ & $4^{\circ} 0$ & $19^{\circ} \mathrm{I}$ & $27 \cdot 3$ & $4 \cdot 8$ & $19 \cdot 8$ & 6.0 & $28 \cdot 9$ & $\mathbf{2 7} \cdot 8$ & 4.0 \\
\hline 1.0 & $28 \cdot 8$ & $4 \cdot 3$ & 17.9 & $40 \cdot 3$ & $6 \cdot 1$ & 19.0 & $4 \cdot 1$ & $34 \%$ & $33 \cdot 6$ & $4 \cdot 2$ \\
\hline $1 \cdot 5$ & $26 \cdot 0$ & 4.0 & $15 \cdot 1$ & $34 \cdot 1$ & $8 \cdot 2$ & $26 \cdot 2$ & $4 \cdot 6$ & $32 \cdot 5$ & $3 I \cdot 6$ & $I \cdot 6$ \\
\hline $2: 0$ & $32 \cdot 3$ & $2 \cdot 7$ & 19.7 & $35 \% 7$ & $6 \cdot 2$ & $22 \cdot 7$ & $2 \% 4$ & $34^{\prime} 5$ & 34.9 & $2 \cdot 3$ \\
\hline $3 \cdot 0$ & $27 \cdot 2$ & $3 \cdot 1$ & $15 \cdot 1$ & $28 \cdot 5$ & $14 \cdot 8$ & $20 \cdot 6$ & $4 \cdot I$ & $29^{\circ} I$ & 39.5 & $2 \cdot 9$ \\
\hline 5.0 & 26.0 & $2 \cdot 8$ & 13.2 & $3 I \cdot 9$ & I $7 \cdot$ I & $18 \cdot 5$ & 2.7 & 27.9 & $43 \cdot 3$ & 4.4 \\
\hline 9.0 & $22 \cdot 0$ & $3 \cdot 8$ & II.O & $28 \cdot 2$ & $24^{\circ} 3$ & 20.0 & $3 \cdot 4$ & $32 \cdot 3$ & $3^{6 \cdot 4}$ & $4 \cdot 8$ \\
\hline 13.0 & 19.5 & $1 \cdot 7$ & $9 \cdot 2$ & $23 \cdot 2$ & 37.7 & $20 \cdot 0$ & 3.7 & 33.8 & 34.4 & 4.7 \\
\hline 19.0 & 19.7 & $2 \cdot 5$ & 10.6 & $26 \cdot 4$ & $27 \cdot 4$ & 18.5 & $I \cdot 2$ & $35^{\circ} \circ$ & $36 \cdot 4$ & 3.7 \\
\hline $25^{\circ} 0$ & $20 \cdot 3$ & $2 \cdot 4$ & $13 \cdot 6$ & 34.7 & 20.4 & $17 \cdot 8$ & 3.0 & $33 \cdot 1$ & $40 \cdot 0$ & $4^{\circ} 4$ \\
\hline $31 \cdot 0$ & $23 \cdot 8$ & $3 \cdot 2$ & 14.7 & 40.9 & $7 \cdot 8$ & 22.5 & $2 \cdot 7$ & 30.7 & $3^{8 \cdot 4}$ & $2 \cdot 3$ \\
\hline
\end{tabular}

of about $12 \%$. The increase in the concentration of $18: 2$ in the cholesteryl ester fraction was less noticeable than that which occurred in the phospholipids, and it was only the sample taken at the $24^{\text {th }} \mathrm{h}$ that showed any appreciable increase in the concentration of $18: 2$.

Expt 2: 'linoleic' acid infusion. The plasma triglycerides showed a marked rise in the concentration of $18: 2$ which began after the 2 nd $h$. A maximum value of $38 \%$ was observed for the concentration of $18: 2$ in the plasma triglycerides at about the $13^{\text {th }} \mathrm{h}$; this value was considerably higher than the maximum concentration obtained in Expt $r$. At the end of the sampling period the concentration of $18: 2$ in the plasma triglycerides had reverted almost to pre-infusion levels. The concentrations of $16: 0$ and $18: 0$, which were both reduced in the plasma triglycerides as a result of the 'linoleic' acid infusion, tended to remain low for the remainder of the experiment. On the other hand, the concentration of $\mathrm{I} 8 \mathrm{I}$ I in the plasma triglycerides at the end of the experiment was considerably higher than that observed before infusion began.

Unlike the results for the maize oil infusion ( $\operatorname{Expt} I$ ), the plasma unesterified fatty 
acid fraction showed no consistent changes in composition as a result of the infusion of 'linoleic' acid.

The cholesteryl ester and phospholipid fractions of the plasma again showed increases in the concentration of $18: 2$ during the experiment. In the plasma phospholipids, the concentration of $18: 2$ increased from a pre-infusion value of about $12 \%$ to a value of $30 \%$ by the end of the experiment. In general, it appeared that this increase in the concentration of $18: 2$ in the plasma phospholipids was accompanied by a decrease in the concentration of $\mathrm{i} 8: \mathrm{r}$.

Table 5. Effect of the infusion of an emulsion of 'linoleic' acid into the rumen of a sheep on the fatty acid compositions (major components, weight percentages of the total) of the plasma cholesteryl esters and phospholipids

\begin{tabular}{|c|c|c|c|c|c|c|c|}
\hline $\begin{array}{l}\text { Time after } \\
\text { beginning } \\
\text { of infusion } \\
\text { (h) }\end{array}$ & I6:0 & I6:I & I 8:0 & $\begin{array}{l}\text { I } 8: \text { I } \\
\text { steryl }\end{array}$ & ${ }^{18: 2}$ & $18: 3$ & $20: 4$ \\
\hline 0 & I $2 \cdot 9$ & $2 \cdot 8$ & $3 \cdot I$ & $43 \cdot 7$ & $23 \cdot 2$ & $3 \cdot 7$ & $2 \cdot 6$ \\
\hline 0.5 & 14.9 & $3 \cdot 0$ & $2 \cdot 8$ & $39 \cdot 3$ & 24.0 & $3 \cdot 4$ & 3.4 \\
\hline I.O & I2.9 & $2 \cdot 6$ & $4 \cdot 2$ & $42 \cdot 9$ & $22 \cdot 0$ & $3 \cdot 8$ & $2 \cdot 3$ \\
\hline$I \cdot 5$ & $15 \cdot 6$ & $3 \cdot 3$ & $5 \cdot 4$ & $40 \cdot 2$ & I 9.4 & 3.4 & $3 \cdot 3$ \\
\hline $2 \cdot 0$ & $14 \cdot 6$ & $2 \cdot 8$ & $3 \cdot 9$ & $42 \cdot I$ & $22 \cdot 0$ & $3 \cdot 6$ & $2 \cdot 4$ \\
\hline $3 \cdot 0$ & $15 \cdot 6$ & $2 \cdot 9$ & $5 \cdot 3$ & $42 \cdot 3$ & 20.4 & $3 \cdot 2$ & $2 \cdot 9$ \\
\hline $5 \cdot 0$ & 13.1 & $2 \cdot 7$ & $2 \cdot 8$ & $48 \cdot 8$ & $22 \cdot 8$ & 3.5 & $2 \cdot 6$ \\
\hline $9 \cdot 0$ & 14.5 & $2 \cdot 8$ & $3 \cdot 5$ & $42 \cdot 1$ & $22 \cdot 3$ & $3 \cdot 4$ & $2 \cdot 7$ \\
\hline $13 \cdot 0$ & 12.7 & $2 \cdot 9$ & 3.8 & $41 \cdot 0$ & $24 \cdot 0$ & $3 \cdot 2$ & $2 \cdot 5$ \\
\hline $19^{\circ} 0$ & 12.8 & 2.5 & $2 \cdot 8$ & 40.5 & $27 \cdot 2$ & $2 \cdot 8$ & $2 \cdot 6$ \\
\hline $25 \cdot 0$ & $12 \cdot 8$ & $2 \cdot 4$ & $3 \cdot 2$ & $39 \cdot 4$ & $29 \cdot 8$ & $2 \cdot 5$ & $2 \cdot 4$ \\
\hline \multirow[t]{2}{*}{$31 \cdot 0$} & $1 I \cdot 2$ & $2 \cdot 4$ & $2 \cdot 4$ & $36 \cdot 7$ & $35^{\circ} \circ$ & 2.5 & $2 \cdot 4$ \\
\hline & \multicolumn{7}{|c|}{ Phospholipids } \\
\hline 0 & 22.9 & $I \cdot 2$ & $24 \cdot 6$ & $25 \cdot 7$ & I I $\cdot 8$ & $I \cdot 6$ & $5 \cdot 0$ \\
\hline 0.5 & $24 \cdot 3$ & $I \cdot 9$ & $23 \cdot 9$ & $26 \cdot 6$ & 10.4 & $I \cdot 7$ & 45 \\
\hline $1 \cdot 0$ & $2 \times 7$ & $2 \cdot 1$ & 247 & $27 \cdot 3$ & $12 \cdot 2$ & 0.2 & $4 \cdot 2$ \\
\hline I. 5 & $23 \cdot 8$ & $2 \cdot 0$ & $25 \cdot 2$ & 25.9 & II.5 & 0.5 & $5 \cdot 4$ \\
\hline $2 \cdot 0$ & $22 \cdot 8$ & $I \cdot 4$ & $24 \cdot 1$ & $26 \cdot 3$ & I I. 8 & $1 \cdot 5$ & $5 \cdot 5$ \\
\hline $3 \cdot 0$ & $22 \cdot 2$ & $1 \cdot 0$ & $24 \cdot 7$ & $28 \cdot 5$ & $12 \cdot 3$ & 0.2 & $5 \cdot 7$ \\
\hline 5.0 & 20.9 & $I \cdot I$ & $24 \cdot 2$ & $27 \cdot 3$ & I $3 \cdot 3$ & $I \cdot 6$ & 5.3 \\
\hline 9.0 & 20.7 & $1 \cdot 5$ & $24 \cdot 8$ & $24^{\circ} 5$ & I $7 \cdot 9$ & $1 \cdot 0$ & $4 \cdot 4$ \\
\hline $13^{\circ} 0$ & $18 \cdot 2$ & 0.9 & 24.2 & $2 \mathrm{I} \cdot 8$ & 22.4 & 0.9 & $5 \cdot 1$ \\
\hline 19.0 & $20 \cdot 3$ & 0.2 & $25 \cdot 1$ & I9.9 & $23 \cdot 6$ & 0.8 & $5 \cdot 3$ \\
\hline 250 & $17 \cdot 2$ & 0.7 & $22 \cdot 7$ & $17 \cdot 8$ & $28 \cdot 1$ & 0.7 & $5 \cdot 7$ \\
\hline $31 \cdot 0$ & 19.0 & 0.9 & $22 \cdot 9$ & $I 7 \cdot 1$ & $29 \cdot 6$ & 0.4 & 5.0 \\
\hline
\end{tabular}

\section{DISCUSSION}

The effects on the plasma lipid composition of the intraruminal infusions of relatively large amounts of either maize oil triglycerides or 'linoleic' acid, whilst similar to those obtained previously when the emulsions were infused into the abomasum (Moore et al. 1969), showed some notable differences. The most noticeable result of the infusions was the fairly rapid incorporation of $18: 2$ into the plasma triglycerides which was accompanied by decreases in the concentrations of $16: 0$ and $18: 0$. The concentration of $18: 2$ in the plasma triglycerides began to increase $2-3 \mathrm{~h}$ after the beginning of the infusions. This was some $2 \mathrm{~h}$ later than the increases noted 
after the maize oil and 'linoleic' acid had been infused into the abomasum (Moore et al. 1969). The delay can presumably be explained by the time taken for the passage of material from the rumen to the abomasum. The maximum concentration of $18: 2$ attained in the plasma triglycerides after the infusion of maize oil into the rumen was considerably lower than the maximum concentrations obtained previously (Moore et al. 1969) when the maize oil was infused into the abomasum. The maximum concentration of $18: 2$ in the plasma triglycerides resulting from the infusion of 'linoleic' acid into the rumen was of the same order as that resulting from the infusion of maize oil into the abomasum (Moore et al. I969). Under normal circumstances a large proportion of the infused $18: 2$ would be hydrogenated to $18: 0$ in the rumen. However, it is possible that, depending on whether the $18: 2$ is administered in the free or esterified form, there is a large difference in the rate at which the rumen microorganisms are capable of hydrogenating the infused $\mathrm{I} 8: 2$. The resulting difference in the amounts of $18: 2$ available for absorption might account for the observed differences between the maximum concentrations of $18: 2$ in the plasma triglycerides after the intraruminal infusions of the maize oil and 'linoleic' acid.

Although the concentrations of $18: 2 \mathrm{i} \mathrm{n}$ the plasma triglycerides had virtually returned to pre-infusion values by the end of both experiments the infusion of maize oil resulted in an increase in the concentration of $\mathrm{I} 8: 0$ in the plasma triglycerides to a value that was considerably greater than that observed in the pre-infusion sample. On the other hand, the infusion of the 'linoleic' acid resulted in an increase in the concentration of $I 8: I$ in the plasma triglycerides to a value that was considerably greater than that found in the pre-infusion sample. Owing to the hydrogenating activity of rumen micro-organisms, it might be expected that the intraruminal infusion of $18: 2$ would result in increased concentrations of $18: 0$ in the rumen contents. However, if there were some interference with the normal hydrogenating process then it is possible that the intraruminal infusion of $18: 2$ resulted in the accumulation in the rumen contents of some intermediate, such as $I 8: \mathrm{I}$ and that this was reflected in the composition of the plasma triglycerides. When $18: 2$ was administered in the form of a triglyceride emulsion, it is possible that hydrolysis of the triglycerides by the rumen micro-organisms resulted in the production of free $18: 2$ at a rate that allowed hydrogenation to proceed more rapidly to completion. Under these conditions, increased concentrations of $18: 0$, rather than $18: \mathrm{I}$, would be expected to occur in the plasma triglycerides (cf. Table 2 ).

The authors wish to thank Miss I. Fisher, Miss E. Skinner and Mr J. McDill for their skilled technical assistance.

\section{REFERENCES}

Garton, G. A., Lough, A. K. \& Vioque, E. (I96I). F. gen. Microbiol. 25, 215.

Moore, J. H., Noble, R. C. \& Steele, W. (I 968), Br. F. Nutr. 22, 68I.

Moore, J. H., Noble, R. C. \& Steele, W. (1969). Br. F. Nutr. 23, I 4 I.

Senior, J. R. (1964). F. Lipid Res. 5, 495.

Tove, S. B. \& Mochrie, R. D. (1963). F. Dairy Sci. 46, 686. 